\title{
Sensitivity Towards Copper: Comparison of Stygal and Surface Water Species' Biomonitoring Performance in Water Quality Surveillance
}

\author{
Christian Grimm* and Almut Gerhardt \\ LimCo International GmbH, Wollmatinger Str. 22, D-78467 Konstanz, Universität Konstanz, Universitätsstraße 10, D-78464 \\ Konstanz, Germany.
}

Received: January 19, 2018; Accepted: February 27, 2018 ; Published: March 03, 2018

*Corresponding author: LimCo International GmbH, Wollmatinger Str. 22, D-78467 Konstanz, Universität Konstanz, Universitätsstraße 10, D-78464 Konstanz, Germany, Tel: +49157 31308691; E-mail: Christian.Grimm@uni-konstanz.de

\begin{abstract}
In a rapidly urbanizing global environment, anthropogenic sources of pollution [e.g., heavy metals, pharmaceuticals] have increasingly contaminated drinking water sources like surface- or groundwater, jeopardizing the safe provision of potable water. Due to the lack of appropriate technology, continuous water surveillance is yet not feasible and while biological early warning systems have shown promising application possibilities, their associated drawbacks limit their practical utility. In this study, two stygal species, Niphargopsis casparyi [Pratz, 1866] and Proasellus slavus [Remy, 1948], were introduced as novel biomonitoring candidates that may reduce maintenance time and cost. Firstly, copper sensitivity of the stygal and two surface species, Gammarus fossarum and Daphnia magna, were defined in acute and chronic toxicity tests. Secondly, using the Multispecies Freshwater Biomonitor [MFB], behavioural responses of all species were examined and compared in multiple copper pulse experiments. Lastly, in a 2-month long field experiment, the applicability of $\mathrm{N}$. casparyi in water quality survey was tested in a local waterworks. Its performance was then compared to G. fossarum and an implemented biomonitor using daphnids. Regarding mortality, copper toxicity tests showed low impact of acute copper pulses onto the two stygal species N. casparyi and P. slavus, but high impact on the surface water species. Chronic exposure led to increased mortality in G. fossarum and P. slavus, but not on N. casparyi. Overall, the pulse and field experiments revealed pronounced, useful, and reproducible behavioural responses towards copper for G. fossarum, N. casparyi, D. magna, but not for P. slavus, making them promising candidates for online biomonitoring.
\end{abstract}

Keywords: Biomonitoring; Drinking Water; Groundwater; stygobionta; Crustacean; Copper;

\section{Introduction}

Potable water sources depend on regional availability, quality, and city size [64]. While Germany [72\%] and Austria [99\%] obtain the majority of their drinking water from groundwater, Norway only derives $13 \%$ from this source. In contrast, developing countries possess huge deficiencies regarding drinking water supply [24]. Six hundred and sixty-three million people do not have access to safe drinking water [E/2016/75] and therefore often suffer from water supply-associated diseases
[24]. Forecasts for 2050 predict addition of 2.5 billion people to the world's urban population with nearly $90 \%$ of the increase concentrated in Asia and Africa [51, 53]. This population boom challenges current potable water supply systems and indicates an urgent need to enhance current water supply capacity [48, 51, 54]. The United Nations [UN] Millennium Development Goals included safe drinking water supply as one specific goal of the 17 UN Sustainable Development Goals for 2030. In order to accommodate the needs of a burgeoning global population in a sustainable manner, current water pollution levels must be drastically reduced and the reuse of water should be reinforced $[47,56]$.

In order to improve water body quality, the European Commission enacted the Water Framework Directive [EC 2000/60/EC] which pledged that all European Union member states would work to achieve good qualitative and quantitative status of all water bodies including groundwater. The directive focuses on the recently revised directive for priority substances, as well as catchment-specific substances [Directive 2013/39/EU] , for which environmental quality standards [EQS] should not be exceeded [2008/105/EC].

Numerous studies reveal increasing levels of heavy metals and other pollutants in ground and surface water a problem that is expected to worsen in the future $[1,21,46,66,68,72]$. For instance, copper concentration in soil and water has increased through anthropogenic discharge including; "smelting, mining, industrial, and domestic waste emission, and the application of fertilizers, sewage sludge, algicides, fungicides, and molluscicides" [11, 21, 63]. Usually, the concentration of copper in lakes and rivers can range from 0.5 to $1,000 \mathrm{ppb}$ [with an average concentration of 10 $\mathrm{ppb}$ ], whereas the average copper concentration in groundwater is typically around $5 \mathrm{ppb}$ though it can be as high as 2,783 ppb [72]. However, the concentration of copper and other pollutants typically fluctuate due to seasonal changes, water level, heavy rainfall or other irregular events [7,61]. Additional risks to human health from polluted water can occur due to specific events like 
chemical spills such as the Sandoz accident at River Rhine in 1986 as well as deficient chemical filtering and bioterrorism [34].

The recommended World Health Organization [WHO] threshold for copper in drinking water is $2 \mathrm{mg} / \mathrm{L}$, a guideline which has been implemented in countries like Germany and Australia. The US regulation is stricter, with the Environmental Protection Agency [EPA]'s "Lead and Copper Rule" [LCR] restricting average copper concentration to a maximum of $1.3 \mathrm{mg} / \mathrm{L}$. To the best of our knowledge, the Federal-Provincial-Territorial Committee on Drinking Water [CDW], published by Health Canada, has defined the lowest threshold of $1 \mathrm{mg} / \mathrm{L}$ of any country.

These types of regulations require the appropriate devices for realization of the implemented limits. Regardless of whether drinking water originates from surface-, ground- or from reuse of sewage water, strict observance of mutually defined thresholds must be controlled to ensure its safety [52]. For instance, in Germany, depending on turnover size, previous test results and type of contaminant, drinking water must be analysed 1-12 times a year. However, generally high levels and continuously fluctuating water body pollution demonstrate the need of strict and continuous controlled water quality to protect sensitive water organisms and ensure safe drinking water sources [23].

In recent decades biological early warning systems [BEWS] using living organisms ranging from bacteria and algae to daphnids, gammarids, and even fish have been developed and tested $[4,5,19,30,33,45,76]$. Cell-based biosensors rely on oxygen consumption [bacterial respirometers], nitrification, carbon dioxide production, bacterial growth, fluorescence, or photosynthesis [5, 14, 49]. In contrast, BEWS implementing animals are based on behavioural changes. High sensitivity towards a broad range of toxicants. Fast response rates of both Daphnidae and Gammaridae qualify them as good species for the use as live biomonitors $[11,13,30,33,76]$.

Gammarus fossarum [Koch, 1835] [Crustacea, Amphipoda] is widely distributed in streams in the Northern hemisphere. As a decomposer, they mainly feed on fallen leaves including their biofilm. Due to high prevalence, G. fossarum is broadly used as a bioindicator for stream water quality control and plays a key role in the aquatic food web $[15,16,57]$. Gammarus has been shown to be sensitive to a variety of toxicants, responding with characteristic behavioural responses such as increased ventilation or decreased locomotion [9, 25, 26, 29, 30, 33, 50]. Gammaridae have been previously used in monitoring Rhine water and the U.S Environmental Protection Agency [EPA] has published 1996 guidelines for gammarid acute toxicity tests [OPPTS 850.1020] $[28,29,75]$. Gammarids have also demonstrated their reliability in numerous ecotoxicological tests [44]. The high sensitivity to a variety of toxicants and ease of breeding, together with its abundant occurrence, qualifies G. fossarum as an ideal species for online monitoring.

The planktonic Daphnia magna [Crustacea, Phyllopoda] lives in fish free open waters and feeds mainly on algae and organic detritus [2]. Therefore, they show a high basal activity. This r-strategist is able to reproduce asexually, resulting in predominantly female clones. If environmental conditions deteriorate, male offspring are produced to incorporate sexual reproduction, leading to diversification and adaptation [20]. The ease of breeding and their utility in a variety of experimental scenarios made daphnids, especially D. magna and D. pulex, one of the most frequently used organisms for ecotoxicological experiments in aquatic systems [74]. This has led to daphnids being used in commercially available online biomonitoring systems $[13,40]$. However, the use of clones, depending on the genotype and previous conditions, may lead to differences in sensitivity towards toxicants $[6,67]$.

In this study, we introduce the groundwater species Niphargopsis casparyi [Pratz, 1866], the stygal relative of Gammaridae and Proasellus slavus [Remy, 1948] as a potential candidate species for online biomonitoring of ground- and drinking water using the Multispecies Freshwater Biomonitor [MFB] [33]. Groundwater is characterized by almost surreal conditions, like exclusion of light, low food or oxygen availability [36]. Therefore, stygobionta are characterized by a slower metabolism which has led to longer life cycles compared to their surface-water relatives [60]. Niphargidae represent the stygal relative of Gammaridae and as some of the largest stygal organisms are predominantly predacious, but also feed on plant detritus or bacterial film. Proasellus slavus [Remy, 1948] [Isopoda, Asellota] feeds mainly on detritus. According to Bork et al. [2008], the specie is a good example to illustrate adaptations to the groundwater environment. Asellus aquaticus, living in surface water, lives up to one year and lays eggs every month. In contrast, P. slavus can live up to 15 years and lays eggs only every 2-4 years [8]. Despite its lower basal activity, which is the trait we are using as indication for wellbeing, low demands and longevity are of great advantage.

Stygal organisms are generally characterized by a lower basal activity, but due to their longevity and their lower energetic demands, they may represent good test subjects for online biomonitoring. Reduction in maintenance would make online biomonitoring more time and cost efficient. Additionally, we expect groundwater Amphipods to be more sensitive to toxic stress, as usually they are exposed to lower toxicant levels compared to surface waters.

\section{Materials and Methods}

\section{Species}

\section{Gammarus fossarum [Koch, 1835]}

A population of $G$. fossarum for these experiments were originally obtained from a creek in Kreuzlingen, Switzerland [coordinates: $47.63311^{\circ} \mathrm{N} 9.16553^{\circ} \mathrm{E}$ ], but since then bred in the laboratory for ca. 4 years at $18^{\circ} \mathrm{C}$ constant temperature in darkness with alder leaves as food source. 


\section{Daphnia magna [Straus, 1820]}

In contrast to OECD guidelines, to circumvent clonal specialization and better mimic natural conditions, three days before an experiment, a bag of live Daphnia magna [POSEIDON - AQUAKULTUR at $10^{\circ} \mathrm{C}$ ] was purchased and under constant temperature transported to the lab. Daphnids were transferred to creek water and sparsely fed with yeast [55]. For the experiments, daphnids of average size [approximately $3 \mathrm{~mm}$ ] were chosen.

\section{Stygal species}

There is so far no established breeding method for groundwater species. Therefore, groundwater animals were caught at least once a month, four days before the start of an experiment in Neuenburg [coordinates: $47.81272^{\circ} \mathrm{N} 7.54740^{\circ} \mathrm{E}$ ] using a tubular probe from ca. $50 \mathrm{~m}$ depth, and transported to the laboratory under constant temperature of $10^{\circ} \mathrm{C}$. In the laboratory, Niphargidae and Proasellus were transferred to separate plastic boxes with pure creek water and kept in the fridge at $10^{\circ} \mathrm{C}$ for acclimation for 4 days. Each week water was exchanged, and a spatula tip of groundwater detritus was added as food source. To reduce the risk of fungal growth, food supply was kept at a minimum. Niphargids [Crustacea, Amphipoda] were examined and based on size and shape of their gnathopods identified as Niphargopsis casparyi [Pratz, 1866], also known as Niphargopsis legeri [Chevreux, 1922].

\section{Creek water}

Creek water, used for both cultivation and experiments, was obtained weekly from Hockgraben in the Lorettowald, Constance [coordinates: $47.66734^{\circ} \mathrm{N} 9.20123^{\circ} \mathrm{E}$ ]. Water quality was tested using the semi-quantitative rapid Field Test Kit AQUANALÖkotest.

\section{Experimental setup}

\section{Acute tests}

All acute toxicity tests were performed at $10^{\circ} \mathrm{C}$ in the dark. Copper solutions were prepared by dilution of $1 \mathrm{mg} / \mathrm{l}$ stock solution of Copper[II]-chloride [SIGMA-ALDRICH] [pH4] with creek water. Instead of determining 48-h EC50 following the OECD guidelines for acute toxicity tests using Daphnia magna, individual daphnids, gammarids, niphargids or isopods were continuously recorded [survival and behaviour] in the Multispecies Freshwater Biomonitor [MFB] over a 24 hour period, allowing for higher data resolution $[33,55]$. Using the MFB, activity of eight individuals per replicate were tracked over 26 hours: after a two hours reference measurement in creek water, the respective copper solution was added. Activity tracking over 24 hours exposure allowed for time to effect analysis, additionally to fixed endpoint evaluation. Thereupon, mortality was determined, and surviving individuals were transferred to polyethylene containers with creek water for a seven-day recovery period. Gammarids, daphnids, niphargids and Proasellus slavus were fed at libitum on an alder leaf, yeast and groundwater fine particulate detritus, respectively. Furthermore, gammarid containers were aerated. Subsequently, activity of the survivors was determined to check for persistent behavioural effects of the short-term copper exposure. For D.magna one replicate with eight individuals each was performed for the following concentrations: Control, 100 $\mu \mathrm{g} / \mathrm{l}, 250 \mu \mathrm{g} / \mathrm{l}$, and $500 \mu \mathrm{g} / \mathrm{l}$. For G. fossarum the following copper concentrations, number of replicates $[\mathrm{r}]$, and animals $[\mathrm{n}]$ were applied: Control [r=6; n=40], $6.25 \mu \mathrm{g} / \mathrm{l}[\mathrm{r}=2 ; \mathrm{n}=8], 12.5 \mu \mathrm{g} / \mathrm{l}[\mathrm{r}=2$; $\mathrm{n}=8$ ], $18 \mu \mathrm{g} / \mathrm{l}$ [r=2; $=16], 25 \mu \mathrm{g} / \mathrm{l}$ [r=2; $\mathrm{n}=8], 36 \mu \mathrm{g} / \mathrm{l}[\mathrm{r}=2 ; \mathrm{n}=16]$, $50 \mu \mathrm{g} / \mathrm{l}[\mathrm{r}=2 ; \mathrm{n}=8], 72 \mu \mathrm{g} / \mathrm{l}[\mathrm{r}=2 ; \mathrm{n}=16], 100 \mu \mathrm{g} / \mathrm{l}$ [r=2; n=8], 144 $\mu \mathrm{g} / \mathrm{l}[\mathrm{r}=1 ; \mathrm{n}=8], 250 \mu \mathrm{g} / \mathrm{l}[\mathrm{r}=4 ; \mathrm{n}=24], 288 \mu \mathrm{g} / \mathrm{l}[\mathrm{r}=2 ; \mathrm{n}=16], 360$ $\mu \mathrm{g} / \mathrm{l}[\mathrm{r}=2 ; \mathrm{n}=16], 500 \mu \mathrm{g} / \mathrm{l}[\mathrm{r}=5 ; \mathrm{n}=32]$, and $720 \mu \mathrm{g} / \mathrm{l}[\mathrm{r}=2 ; \mathrm{n}=16]$. For N. casparyi the following copper concentrations, number of replicates [r], and animals [n] were applied: Control [r=5; $\mathrm{n}=32]$, $6.25 \mu \mathrm{g} / \mathrm{l}[\mathrm{r}=2 ; \mathrm{n}=8], 12.5 \mu \mathrm{g} / \mathrm{l}[\mathrm{r}=2 ; \mathrm{n}=8], 18 \mu \mathrm{g} / \mathrm{l}[\mathrm{r}=1 ; \mathrm{n}=8], 25$ $\mu \mathrm{g} / \mathrm{l}[\mathrm{r}=2 ; \mathrm{n}=8$ ], $36 \mu \mathrm{g} / \mathrm{l}[\mathrm{r}=1 ; \mathrm{n}=8$ ], $50 \mu \mathrm{g} / \mathrm{l}[\mathrm{r}=2 ; \mathrm{n}=8], 72 \mu \mathrm{g} / \mathrm{l}$ [r=1; n=8], $100 \mu \mathrm{g} / \mathrm{l}[\mathrm{r}=2 ; \mathrm{n}=8], 144 \mu \mathrm{g} / \mathrm{l}[\mathrm{r}=1 ; \mathrm{n}=8], 250 \mu \mathrm{g} / \mathrm{l}$ [r=4; n=22], $288 \mu \mathrm{g} / \mathrm{l}[\mathrm{r}=1 ; \mathrm{n}=8], 360 \mu \mathrm{g} / \mathrm{l}[\mathrm{r}=1 ; \mathrm{n}=8], 500 \mu \mathrm{g} / \mathrm{l}$ [r=4; $=24]$, and $720 \mu \mathrm{g} / \mathrm{l}[\mathrm{r}=1 ; \mathrm{n}=8]$. For P. slavus the following copper concentrations, number of replicates [r], and animals [n] were applied: Control [r=3; r=24], $18 \mu \mathrm{g} / \mathrm{l}[\mathrm{r}=2 ; \mathrm{n}=16], 36 \mu \mathrm{g} / \mathrm{l}$ [r=2; n=16], $72 \mu \mathrm{g} / \mathrm{l}[\mathrm{r}=2 ; \mathrm{n}=16], 144 \mu \mathrm{g} / \mathrm{l}[\mathrm{r}=2 ; \mathrm{n}=16], 250 \mu \mathrm{g} / \mathrm{l}$ [r=1;n=8], $288 \mu \mathrm{g} / \mathrm{l}[\mathrm{r}=1 ; \mathrm{n}=8], 360 \mu \mathrm{g} / \mathrm{l}[\mathrm{r}=2 ; \mathrm{n}=16], 500 \mu \mathrm{g} / \mathrm{l}$ [r=1; n=8], and $720 \mu \mathrm{g} / \mathrm{l}[\mathrm{r}=2 ; \mathrm{n}=16]$. For D.magna, one replicate of Control, $100 \mu \mathrm{g} / \mathrm{l}, 250 \mu \mathrm{g} / \mathrm{L}$, and $500 \mu \mathrm{g} / \mathrm{l}$ copper was tested.

\section{Chronic tests}

Response to chronic toxicity of G.fossarum, N. casparyi, and P. slavus was tested in repeated pulse experiments over 4-6 weeks. Tests were performed at $10^{\circ} \mathrm{C}$ in the dark. For P. slavus, 2 replicates with five individuals each were exposed to $0 \mu \mathrm{g} / \mathrm{l}$ [Control], $100 \mu \mathrm{g} / \mathrm{l}, 250 \mu \mathrm{g} / \mathrm{l}, 500 \mu \mathrm{g} / \mathrm{l}$, and $1000 \mu \mathrm{g} / \mathrm{l}$ copper. For G. fossarum and N. casparyi, 2-4 replicates with 4-8 individuals each were performed. For G. fossarum the following concentrations, number of replicates [r], and animals [n] were applied: Control [r=8; $\mathrm{n}=41], 50 \mu \mathrm{g} / \mathrm{l}[\mathrm{r}=7 ; \mathrm{n}=33], 100 \mu \mathrm{g} / \mathrm{l}[\mathrm{r}=3$; $\mathrm{n}=16], 250 \mu \mathrm{g} / \mathrm{l}[\mathrm{r}=9 ; \mathrm{n}=49], 500 \mu \mathrm{g} / \mathrm{l}[\mathrm{r}=5 ; \mathrm{n}=25]$ copper. For $\mathrm{N}$. casparyi the following concentrations, number of replicates $[\mathrm{r}]$, and animals [n] were applied: Control [r=2; $\mathrm{n}=8], 50 \mu \mathrm{g} / \mathrm{l}[\mathrm{r}=2$; $\mathrm{n}=8], 100 \mu \mathrm{g} / \mathrm{l}$ [r=3; n=16], and $250 \mu \mathrm{g} / \mathrm{l}[\mathrm{r}=3 ; \mathrm{n}=16]$ copper.

Replicates of up to five individuals were placed in a beaker [250 ml] in a total volume of $200 \mathrm{ml}$ solution. Replicates of more than five individuals were placed in $600 \mathrm{ml}$ beakers in a volume of $400 \mathrm{ml}$. Beakers were sealed with foil and aerated for G. fossarum. Copper-solutions were freshly prepared and renewed weekly. G. fossarum was fed on a piece of an alder leaf [d $3 \mathrm{~cm}$ ], with the loss providing a rough estimation of feeding behaviour at the end of the exposure. Stygal species fed on fine detritus which was sampled together with the animals. Mortality of all species was checked twice a week. Furthermore, activity of G.fossarum and $\mathrm{N}$. casparyi was measured twice a week for 2 hours in the MFB to check for changes in activity patterns throughout the exposure time. Therefore, 2-3 individuals, randomly chosen from each of the replicates, were inserted individually in the test chambers in copper-free creek water using a plastic pipette. 


\section{Water works}

Waterworks A [name withheld for privacy] obtains the water from Lake Constance. Raw water originates from $40 \mathrm{~m}$ depth, $700 \mathrm{~m}$ distant to the lakeside. Due to high water quality, water is only filtered through micro- and sand filters and disinfected with ozone. Water quality is regularly determined according to the German TrinkwV. Furthermore, physicochemical parameters, such as temperature $\left[{ }^{\circ} \mathrm{C}\right]$, fluorescence $[\mathrm{ppm}], \mathrm{pH}$, turbidity [FNU] and spectral absorption coefficient [German: SAK] $[\mathrm{e} / \mathrm{m}]$ are continuously controlled. Although not mandatory, the water purification plant has operated a biomonitor using Daphnia magna for many years to ensure drinking water safety and bounteously provided us with both their physicochemical parameters and the Daphnia toxicity index.

Over the period of two months, using the MFB, locomotion and ventilation activity of Niphargopsis casparyi was continuously monitored. Test chambers were placed in a 20-l flow-through aquarium with a flow-through rate of $\sim 3.6 \mathrm{l} / \mathrm{min}$ raw water, as to be seen in Figure 1. Trace length was determined as four minutes, followed by a pause of six minutes. Two types of behaviour were defined, covering movements between 0 and $5 \mathrm{~Hz}$. Band 1 summarizes the impedance changes with frequencies of $0.5-2 \mathrm{~Hz}$, representing locomotion. Band 2 summarizes higher frequencies from $2.5-5 \mathrm{~Hz}$, which portray ventilation. Low capture rates for niphargids constrained us to implement only three individuals in December. In January, subject number could be increased to eight. The setup and survival of niphargids was checked weekly. Due to the low capture in December, only dead animals were replaced. In January, if any animals died, all were replaced.

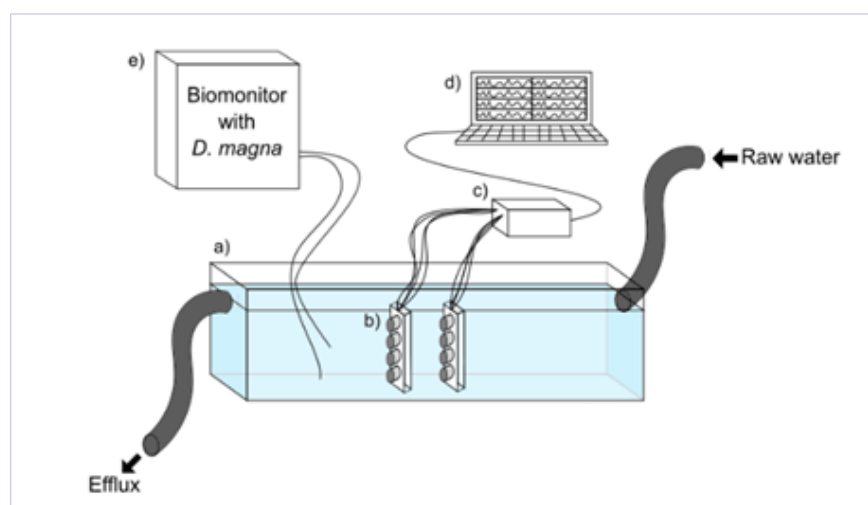

Figure 1: Setup during the field experiment. The figure depicts the construction in the waterworks. a) 20-l flow-through aquarium, b) eight MFB test chambers, c) impedance and A/D converter, d) Laptop for online biomonitoring, e) Biomonitor with D. magna

\section{Pulse experiments}

The biomonitor with D. magna [BD] and the MFB with niphargids and gammarids were tested simultaneously in two $\mathrm{Cu}$-pulses. Therefore, the water afflux to the BD was taken from the MFB aquarium to assure usage of the same water for both test systems. However, flow for BD was adjusted to $0.5-2 \mathrm{l} / \mathrm{h}$ and water was heated to $20^{\circ} \mathrm{C}$. For the time of $\mathrm{Cu}$-exposure in both experiments, inflow into the aquarium was stopped to ensure a constant concentration. Including both the chamber and tube volumes, the total volume was determined as being $19.875 \mathrm{l}$. A copper pulse was given as follows: Approximately $500 \mathrm{ml}$ water was taken from the aquarium and mixed with the respective amount of freshly prepared stock solution $\left[1 \mathrm{~g} / \mathrm{l} \mathrm{Cu}^{2}\right.$-Chl, SIGMAALDRICH, pH 4] to yield the desired concentration. The copper solution was transferred back to the aquarium and stirred with a wooden staff for $2 \mathrm{~min}$.

\section{Stepwise increasing $\mathrm{Cu}$ pulse}

Before the pulse, four gammarids and four niphargids acclimatized for two days in the streaming raw water in the waterworks. During the first experiment we compared the behavioural responses of G. fossarum, N. casparyi and D. magna in the BD to four subsequently increasing concentrations of 100 $\mu \mathrm{g} / \mathrm{l}, 250 \mu \mathrm{g} / \mathrm{l}, 500 \mu \mathrm{g} / \mathrm{l}$ and $1000 \mu \mathrm{g} / \mathrm{l}$ copper, each lasting for 2-2.5 hours until $1000 \mu \mathrm{g} / \mathrm{l}$ was reached, which lasted overnight. The next day water inflow was restarted, and the animals could recover in slowly decreasing $\mathrm{Cu}$-concentrations.

Alarm settings for the stepwise increasing $\mathrm{Cu}$-pulse proceeded with the following. Immobility signal was elicited if $25 \%$ of the channels did not show any activity [mortality alarm]. Changes in behaviour were calculated as deviations from the prediction based on the last 3 records [ARIMA model]. The software gave a behavioural alarm if the activity measurement deviated once for more than $10 \%$ or $5 \%$ from the mean of the last 3 recordings of Band 1 [locomotion] or Band 2 [ventilation], respectively.

\section{$500 \mu \mathrm{g} / \mathrm{l}$ Cu pulse}

The setup was the same as during the stepwise increasing copper pulse. Four gammarids and four daphnids [POSEIDON - AQUAKULTUR] acclimatized for 2.5 hours in the MFB test chambers in raw water from the waterworks intake. Gammarids and daphnids were compared using the same monitoring technique[MFB] under the same conditions regarding flow and temperature. Again, the BD was operated with the same water. After acclimatization, copper exposure was initiated as described above and lasted overnight without a recovery phase thereafter.

Furthermore, alarm settings and data resolution in the MFBsoftware were changed. One measurement lasted four minutes followed by only two minutes pause [instead of 6 minutes before] in order to gain higher time resolution of the MFB-Biomonitor. Immobility alarm was elicited by $25 \%$ [instead of $50 \%$ before] of the individuals. The prediction was calculated using the last five measurements [instead of 3 recordings], in order to incorporate the variability of the individuals and thus reduce false positive alarms. Tolerated deviation from Band 1 [locomotion] and Band 2 [ventilation] were $10 \%$ and $3 \%$, respectively.

\section{Data treatment}

\section{Acute toxicity}

Activity during acute, chronic, or the field experiments was 
measured using the MFB_V51_DSP software and exported to XLS and SigmaPlot. Plots displaying activity over time were prepared using GraphPad Prism, Version 5.01.

SigmaPlot [Systat Software, San Jose, CA] was used to perform statistical analysis to test for significant behavioural differences between the replicates upon acute copper exposure. Since the replicates were unpaired and most data sets did not pass the normal distribution test [Shapiro-Wilk], the non-parametric oneway analysis of variance on ranks [Kruskal Wallis] with pairwise multiple comparisons [Tukey] was applied. Furthermore, LC50 for different endpoints was determined using GraphPad Prism Version 5.01. LC50 for G.fossarum and E.serrulatus could be defined by the "log[inhibitor] vs. response - Variable slope" analysis. Lower number of replicates and tested concentration levels restricted us to calculate LC50 for P.slavus using the "log[inhibitor] vs. response" function with a standard slope of -1. The 24-h LC50 of D.magna was determined with the Probit method using MS Excel Version 2016.

\section{Chronic toxicity}

Behavioural changes due to chronic copper exposure was examined with SigmaPlot using the Friedmann test for repeated measures and Dunnets' posttest. All subsequent measurements of a replicate were compared to their reference values before exposure started. Scatter plots displaying activity over time of exposure were prepared using GraphPad Prism, Version 5.01.

Used solutions were weekly analysed using high performance liquid chromatography [HPLC] at $280 \mathrm{~nm}$ by Technologiezentrum Wasser [TZW] in Karlsruhe.

\section{Species sensitivity distribution}

Literature and our data was compiled in a species sensitivity distribution of representatives of the lower trophic levels [Figure 10]. In order to achieve a realistic estimate about both chronic and acute consequences of copper pollution, data was not sorted for certain exposure times [58]. Species sensitivity distribution was created with "log[inhibitor] vs. response - Variable slope" of GraphPad Prism. The resulting formula was used to determine hazardous concentration for 5\% [HC5] and the potentially affected fraction [PAF].

\section{Results}

\section{Creek water}

Results, as well as the threshold for drinking water ordinance [TWV], are shown in Table 1. Furthermore, $\mathrm{pH}$ and total hardness were determined as being 7.7 and $8^{\circ} \mathrm{dH}\left[143 \mathrm{mg} / \mathrm{L}\right.$ as $\left.\mathrm{CaCO}^{3}\right]$, respectively. The results show high water quality regarding the tested pollutants and thus exclude interference with experiments.

\section{Toxicity}

In acute and chronic experiments, LC50 for different timepoints were defined for G.fossarum, D. magna, P. slavus, and compared to E. serrulatus [Gerhardt, unpubl. Data] [Figure 2]. For
Table 1: Results of water quality control from Hockgraben using AQUANAL-Ökotest

\begin{tabular}{|c|c|c|}
\hline Compound & Measured [mg/l] & Threshold (TWV) [mg/l] \\
\hline Ammonium & $<0.05$ & $<0.5$ \\
\hline Nitrate & 0 & $<50$ \\
\hline Nitrite & $<0.02$ & $<0.1$ \\
\hline Phosphate & $<0.5$ & $<5.2$ \\
\hline
\end{tabular}

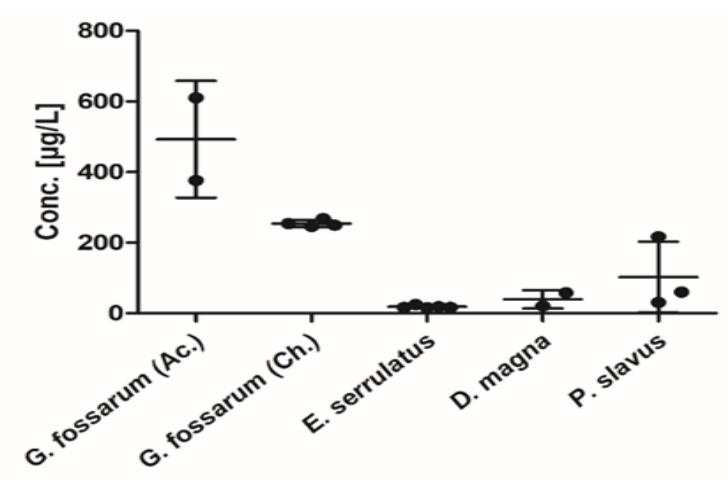

Figure 2: Acute and chronic LC50 for G. fossarum is compared to acute toxicity of E. serrulatus (Gerhardt, unpubl. data) and D. magna, and chronic LC50 of P. slavus. The scatter plot shows individual LC50 values and mean \pm SD.

G. fossarum the 24-h LC50 was calculated as being $610 \mu \mathrm{g} / \mathrm{l}$ and $376 \mu \mathrm{g} / \mathrm{l}$ after seven days recovery, indicating long-time impact of a single pulse. In chronic experiments over four weeks LC50s after each week were determined. The LC50 decreased from 268 $\mu \mathrm{g} / \mathrm{l}[1 \mathrm{w}$ ] to $254 \mu \mathrm{g} / \mathrm{l}[2 \mathrm{w}$ ], $250 \mu \mathrm{g} / \mathrm{l}[3 \mathrm{w}$ ] to $246 \mu \mathrm{g} / \mathrm{l}[4 \mathrm{w}$ ] during the exposure. P. slavus did not show increased mortality upon acute pulses. First unambiguous LC50 determination was possible after four weeks. LC50 after four, five, and six weeks exposure were $217 \mu \mathrm{g} / \mathrm{l}, 60 \mu \mathrm{g} / \mathrm{L}$, and $31 \mu \mathrm{g} / \mathrm{l}$, respectively. Our preliminary data for 24-h LC50 of D. magna were $58 \mu \mathrm{g} / \mathrm{l}$ after exposure and $21 \mu \mathrm{g} / \mathrm{l}$ after seven days recovery. Mortality of N.casparyi was very low in acute tests and generally uniformly high in chronic toxicity tests across all tested concentrations including controls. Therefore, LC50 could not be determined.

\section{Behaviour}

\section{Acute}

Activity measurements during the laboratory acute copper pulses revealed no significant deviation to the control in P. slavus, although exposed replicates showed weak increase of locomotion. The same applies for G. fossarum and N. casparyi upon exposure to copper concentrations up to $360 \mu \mathrm{g} / \mathrm{l}$. First alterations started upon $500 \mu \mathrm{g} / \mathrm{l}$ copper. Despite preliminary experiments with D. magna showed already effects to $250 \mu \mathrm{g} / \mathrm{l}$ copper, for comparison reasons, reaction of G. fossarum, N. casparyi, and D. magna to $500 \mu \mathrm{g} / \mathrm{l}$ copper are illustrated in Figure 3. While G. fossarum and $\mathrm{N}$. casparyi first responded with a decrease in variability and an increase in locomotion after start of exposure [vertical red line], all species showed strong reduction in locomotion 

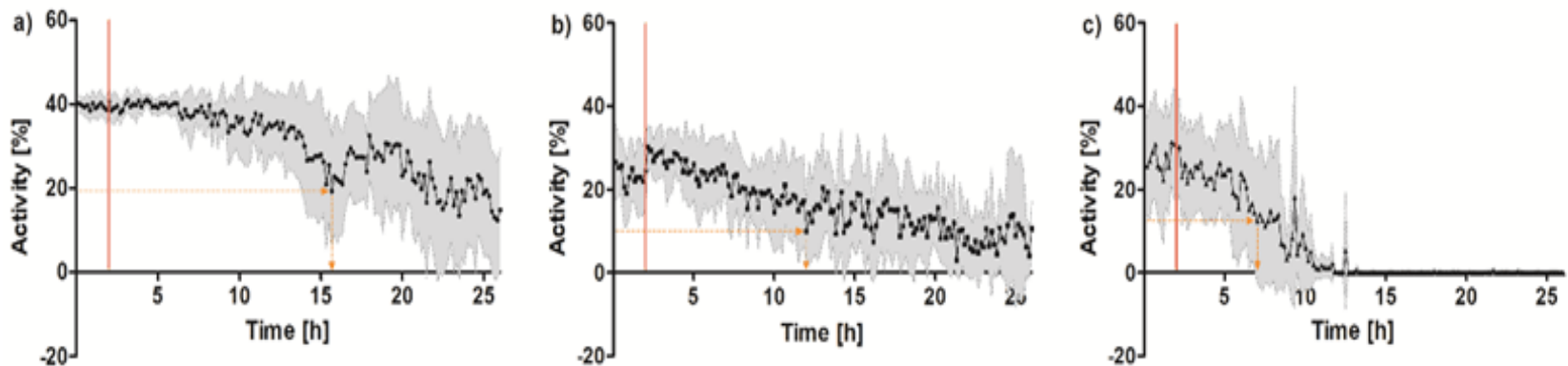

Figure 2: Acute and chronic LC50 for G. fossarum is compared to acute toxicity of E. serrulatus (Gerhardt, unpubl. data) and D. magna, and chronic LC50 of P. slavus. The scatter plot shows individual LC50 values and mean \pm SD.

over the rest of the 24 hours of exposure. Additionally to fixed endpoint evaluation, continuous activity tracking allowed for determination of the time until activity reduced by 50\% [ET50, marked with an orange arrow] from the reference measurements. A comparison of ET50 of the three species is compiled in Figure 4 Mean ET50 values for G. fossarum, N. casparyi, and D.magna are $9.9 \mathrm{~h}, 6.5 \mathrm{~h}$, and 5.8 hours, respectively.

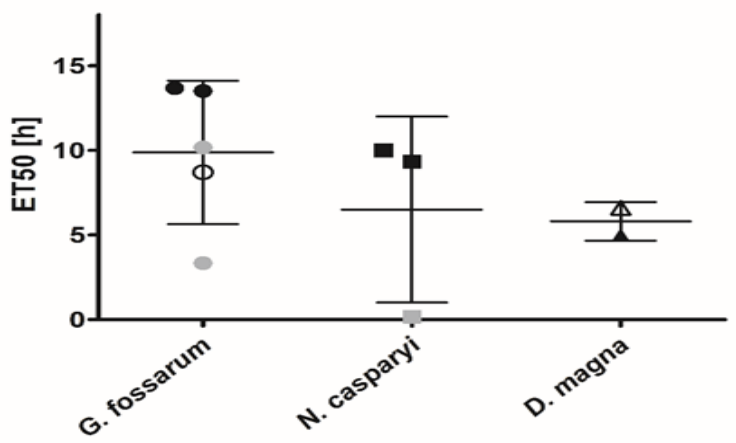

Figure 4: ET50 comparison to $500 \mu \mathrm{g} / \mathrm{L}$ copper. The graph illustrates the time until copper exposure lead to reduction of activity by $50 \%$. Black and grey values originate from experiments of C. Grimm and N. Leubner, respectively. Filled dots are derived from laboratory, hollow dots from field experiments. The scatter plot shows individual values and their mean \pm SD.

\section{Chronic}

Activity of $G$. fossarum and $N$. casparyi over the course of chronic exposure is shown in Figure 5. Examination of the activity over 28 days exposure did not reveal any effect on neither of the species. G. fossarum demonstrates relatively consistent and high activity during the measurements, although occasionally displays lower levels of locomotion in higher copper concentrations. Nevertheless, the picture was not uniform over the course of the experiment. Semiquantitative analysis of the alder leaves, the food of G.fossarum showed strong reduced feeding in 250 $\mu \mathrm{g} / \mathrm{L}$ and $500 \mu \mathrm{g} / \mathrm{L}$ replicates, but not in lower concentrations. Furthermore, a general observation was reduced activity and avoidance response during changing solutions or handling the individuals in these concentrations. In comparison, N. casparyi was generally less active and highly variable across all replicates.
Thus an effect of chronic copper exposure was not evident. Due to the lack of an adequate method, an effect on feeding could not be examined. A reduction of flight response during handling could not be observed.
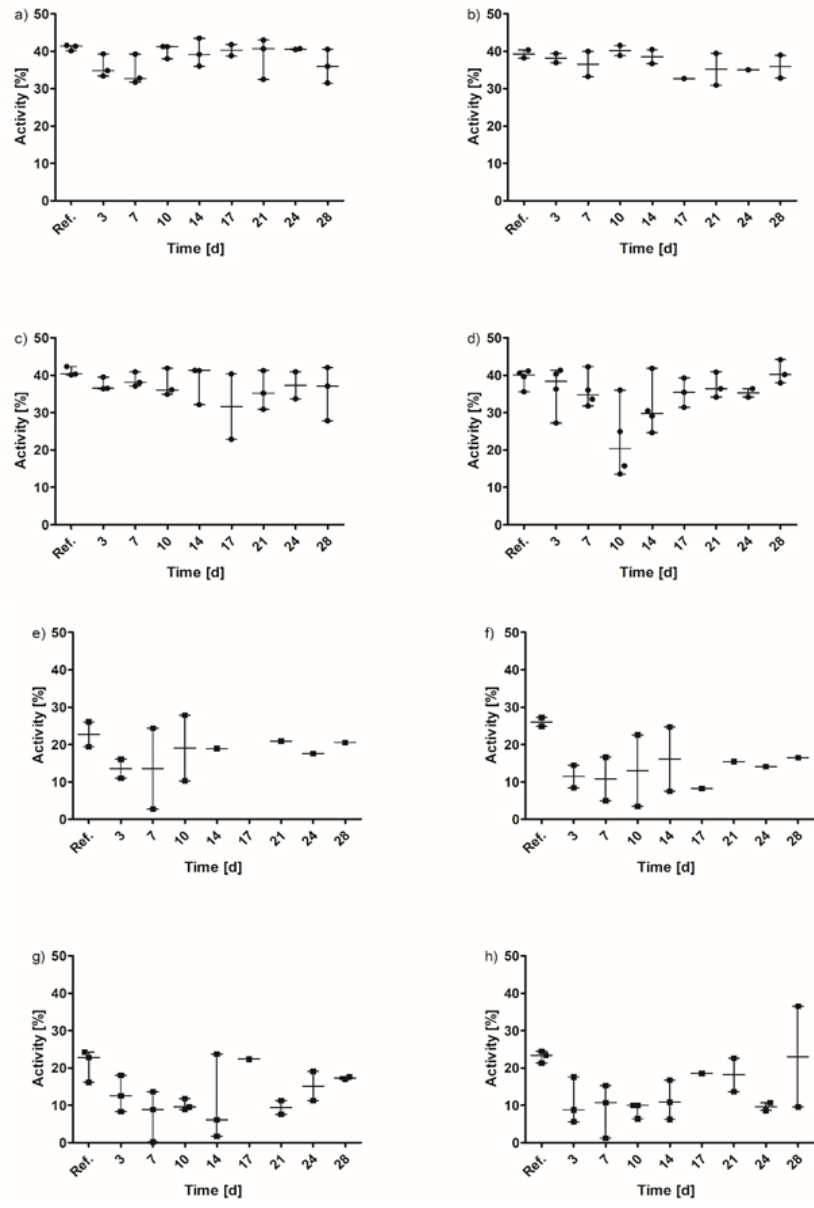

Figure 5: Behaviour during chronic exposure. a-d represent control, 50 $\mu \mathrm{g} / \mathrm{L}, 100 \mu \mathrm{g} / \mathrm{L}$, and $250 \mu \mathrm{g} / \mathrm{L}$ replicates of $G$. fossarum, respectively. e-h represent the same for $N$. casparyi. The graphs illustrate activity over the time of 28 days exposure. Each point depicts mean activity of one replicate ( $\mathrm{n}=4-8$ individuals) over a two hours period. The scatter plot shows median and range of data. 


\section{Long term measurements}

During the field experiment in the waterworks in December 2016 and January 2017 physicochemical data of temperature, fluorescence, $\mathrm{pH}$, turbidity, and spectral absorption coefficient [German: SAK] of the raw water were provided. Turbidity is measured via $90^{\circ}$ light-scattering according to ISO 7027 and is denoted in Formazine Nephelometric Units [FNU]. Physicochemical data were $6.19 \pm 0.82{ }^{\circ} \mathrm{C}, 0.6 \pm 0.03 \mathrm{ppm}$, $8.01 \pm 0.07,0.46 \pm 0.13 \mathrm{FNU}$ and $2.25 \pm 0.27 \mathrm{e} / \mathrm{m}$. Except for a single situation, values were in normal range with low variability, which ensures no influence on the field experiment.

Since all four field monitoring experiments showed similar and reproducible results, two are presented exemplary in the following. Figure 6 depicts the averaged locomotion [black] and ventilation [green] of niphargids as well as the Daphnia Biomonitor toxicity index [BD TI] [dark red]. Over the first 13 days exposure to raw water intake from lake Constance, niphargids' locomotive activity was on average of $13 \% \pm 7 \%$ SD [n=3]. High variability was due to one individual which only occasionally showed activity right from the beginning of the experiment. On day three niphargids started and continued to show increased ventilation, a behaviour rarely seen in N. casparyi, that normally indicates stress, which in turn was affirmed with a reaction of the BD TI. A comparison to the physicochemical data revealed a single peak in $\mathrm{pH}$ and a parallel drop in SAK, during this period. $\mathrm{pH}$ increased within two hours from 7.96 to 8.91 and dropped in the following hour back to 7.9. SAK decreased retrograde to 0.01 and rose back to 1.97. Simultaneous to the increase in $\mathrm{pH}$, niphargids started ventilating. Although stress ventilation activity decreased after two days, niphargids kept ventilating occasionally, indicating sustained and undefined water contamination or a long-lasting impact. The same was true for the daphnids until they were replaced on the 7th day. Afterwards the BD presented basal values. Throughout the remaining six days, fluctuation in locomotive activity appeared to increase, indicating an avoidance response. On the last day an increase in BD TI coincided with increasing ventilation and fluctuating locomotion in the niphargids. This second suspicious coincidence could not be attributed to physicochemical parameters.
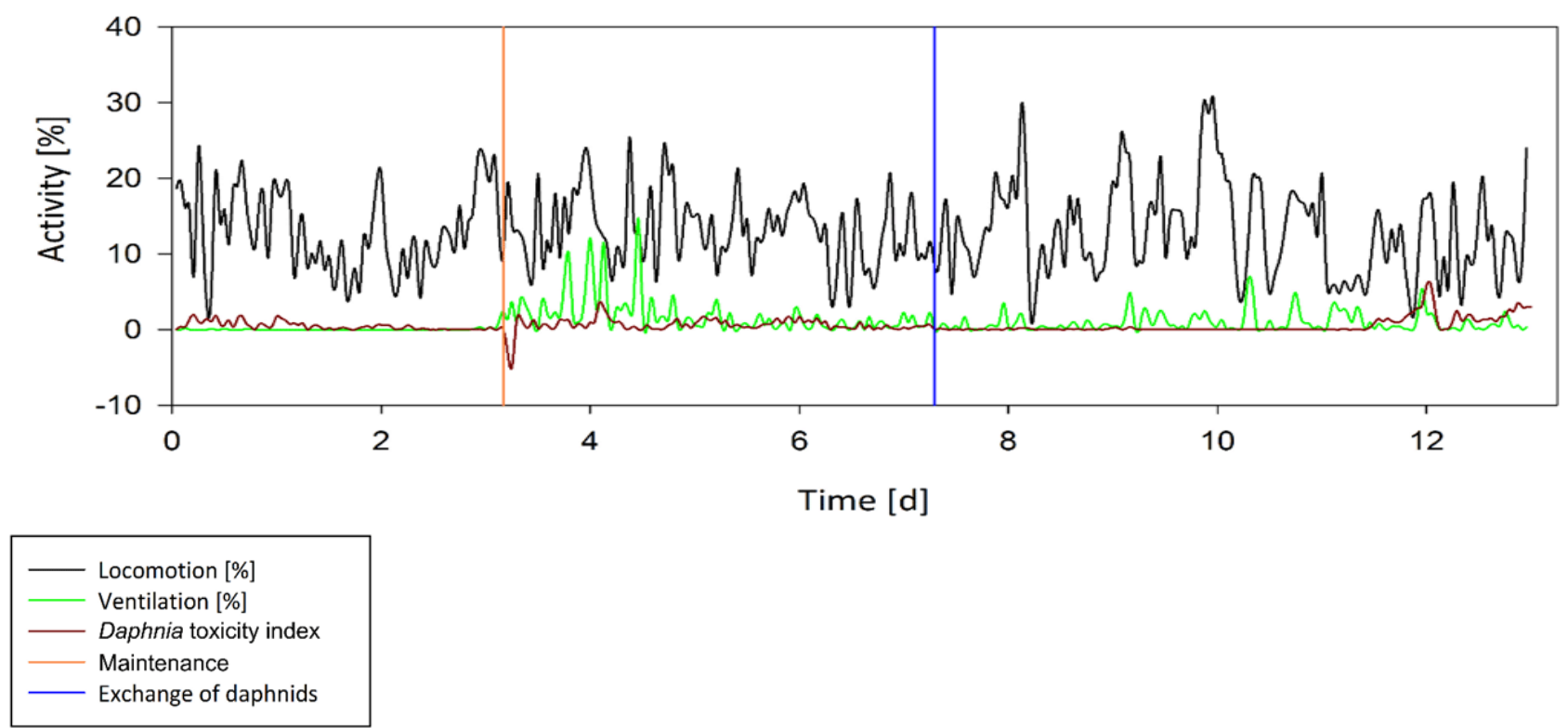

Figure 6: Long term activity measurement of $N$. casparyi in a drinking water purification plant. The figure depicts the averaged locomotion (black) and ventilation (green) of three niphargids over 13 days, from the 16th until the 29th of December. Daphnia toxicity index (BD TI) is illustrated in red. Vertical orange and blue lines mark maintenance of the $\mathrm{BD}$ and exchange of its daphnids, respectively.

The second timeframe [Figure 7] lasted from 12th to the 26th of January 2017. During this period eight niphargids were employed. Apparent from the figure and marked with a dark green vertical line, the timeframe is split in two parts. Because of the higher number of individuals locomotive activity was more stable and less fluctuating. On the first two days of this period average activity was $23 \% \pm 4 \%$. On the second day coinciding with an exchange of daphnids marked with a blue vertical line and a subsequent increase in the BD TI, niphargids showed slightly increased levels of ventilation. After the ventilation and
BD TI returned to basal levels on the end of the second day, niphargids' locomotive activity started to decrease. Over the following five days locomotion decreased wavelike.to an average activity of $12 \% \pm 5 \%$. High levels of BD TI on the fourth day was due to prolonged maintenance of the $\mathrm{BD}$. During the subsequent three days niphargids showed again slightly increased levels of ventilation. On the weekly setup check [day 7] the three individuals were identified dead and the rest appeared weak. All animals were then replaced as a result. 

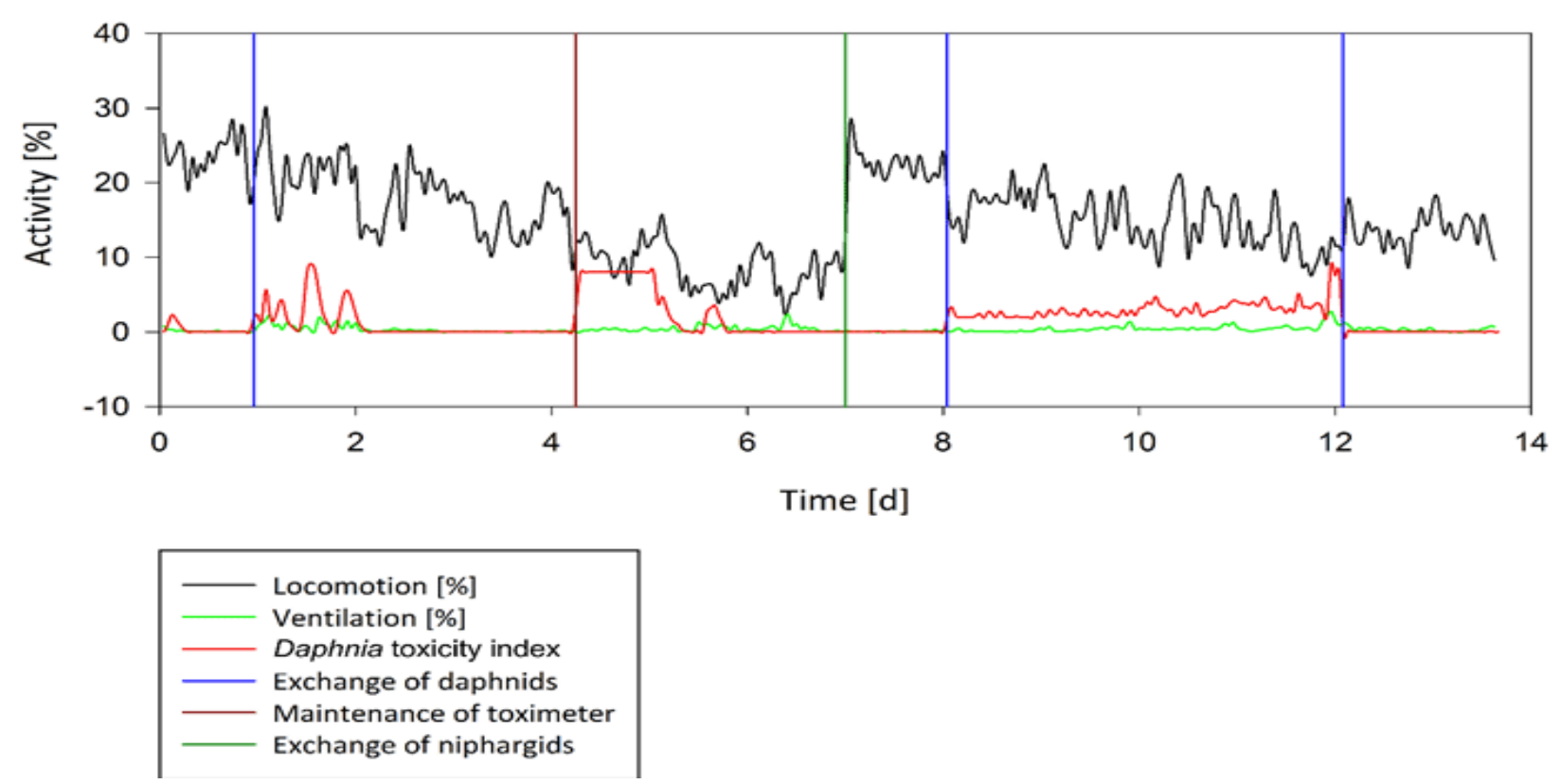

Figure 7: Long term activity measurement of $N$. casparyi in a drinking water purification plant. The figure depicts the averaged locomotion (black) and ventilation (green) of eight niphargids from 12th to the 26th of January 2017. Daphnia toxicity index (BD TI) is illustrated in red. Vertical dark red, blue and dark green lines indicate maintenance of $\mathrm{BD}$, exchange of its daphnids or niphargids of MFB, respectively.

New employed individuals of niphargids showed high levels of locomotion similar to the beginning of the first period. Average locomotive activity of the new employed individuals was $23 \% \pm 3 \%$. In the morning of the second day daphnids of the BD biomonitor were replaced. After replacement the BD showed increased values of the toxic index. Parallel to the maintenance of the BD, we registered a harsh drop in activity and occasional ventilation activity in the niphargids. Possibly during maintenance of the BD niphargids' aquarium was disturbed, thus leading to unusual activity patterns. During these four days, the BD was maintained again and the niphargids' locomotion level further decreased slowly. The average niphargids' locomotion level dropped to $15 \% \pm 4 \%$.

\section{Pulse experiments}

\section{Stepwise increasing Cu pulse}

Both G. fossarum and N. casparyi showed rather fluctuating locomotion and occasional low levels of ventilation over the 48-h acclimatization in the MFB [Figure 8]. During the last eight hours acclimatization, gammarids and niphargids showed $35 \% \pm 6 \%$ and $16 \% \pm 4 \%$ activity, respectively. Upon the first copper pulse of $100 \mu \mathrm{g} / \mathrm{l}$, gammarids and niphargids reacted with a pronounced increase and stable level of high locomotory activity. During this period, average activity was $39 \% \pm 1 \%$ and $23 \% \pm 2 \%$, respectively. [Figure $8 \mathrm{~b}$ ] shows exemplary the activity of an individual of G. fossarum. Over the four minutes measuring interval, the gammarid showed almost constantly high amplitude signals which is typical for locomotion. This elevated activity was sustained for 6.5 hours until copper concentration was increased to $1000 \mu \mathrm{g} / \mathrm{l}$. Elevated activity indicates avoidance behaviour due to the increasing exposure. In contrast, the BD TI recorded increased values first upon the $500 \mu \mathrm{g} / \mathrm{l}$ pulse 4.5 hours later than the other two species. Within 70 minutes in $1000 \mu \mathrm{g} / \mathrm{l}$, gammarids and niphargids started to rapidly decrease in activity. 2.5 hours and thereafter, both species likewise showed about $50 \%$ decrease in activity. Parallel the BD biomonitor reached highest values. Figure 4 [b, c, d] shows exemplary the raw activity signals of one individual of G. fossarum. The frequency of high amplitudes [locomotion] decreased, suggesting that movements became weaker and less often. In contrast, low amplitude signals of high signal frequency [ventilation] increased [marked with an asterix]. After a total of 7.5 and 6.2 hours in the highest concentration, gammarids and niphargids did not show any locomotory activity. [Figure $8 \mathrm{~d}$ ] depicts exemplary the activity of a gammarid during this period. Movements were rare and weak. Simultaneously the BD TI decreased to zero.

The next day, 22 hours after exposure started, water inflow was enabled and marked with a blue vertical line. With an inflow of $\sim 3.6 \mathrm{l} / \mathrm{min}$ the concentration halves every 5.5 minutes. Assuming no contamination of the raw water, concentration in the aquarium was below $10 \mu \mathrm{g} / \mathrm{l}$ within 37 minutes. During the two days recovery period only one gammarid survived. This gammarid was weak and occasionally showed locomotion. In contrast, two niphargids survived the copper pulse and the subsequent recovery period. The two niphargids were more active during the recovery phase and were stronger when the experiment was stopped. The locomotion patterns of the two species during the recovery period were very similar but both niphargids were way 


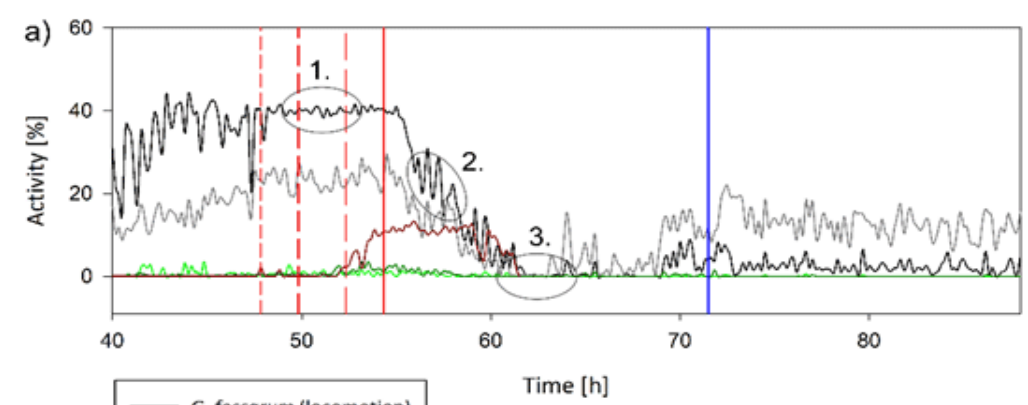

\begin{tabular}{|l|}
\hline G. fossarum (locomotion) \\
G. fossarum (ventilation) \\
N. casparyi (locomotion) \\
N. casparyi (ventilation) \\
Daphnia toxicity index
\end{tabular}

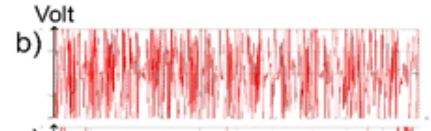

c)

d)

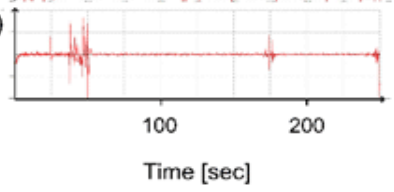

Figure 8: Result of the stepwise increasing copper pulse. In order to increase resolution, the acclimatization period is largely left out. The left figure (Fig. 4a) shows the average locomotion (black), ventilation (bright green) of G. fossarum, locomotion (grey) and ventilation (dark green) of $N$. casparyi. Furthermore, the Daphnia toxicity index (BD TI) is illustrated in dark red. Bright red vertical lines mark the start of I) $100 \mu \mathrm{g} / \mathrm{l}$, II) $250 \mu \mathrm{g} / \mathrm{l}$, III) 500 $\mu \mathrm{g} / \mathrm{l}$ and IV) $1000 \mu \mathrm{g} / \mathrm{l}$ copper pulse. Blue vertical line indicates start of recovery. The right figure (Fig. 4 b,c,d) depicts exemplary samples of activity of G. fossarum over the period of the pulse. b) elevated activity during first three pulses. c) decreasing activity under in $1000 \mu \mathrm{g} / \mathrm{L}$. d) very low activity after $5.5 \mathrm{~h}$ of $1000 \mu \mathrm{g} / \mathrm{L}$. The graphs show voltage [V] over the time.

more active than the gammarid. Gammarid activity ranged from $0 \%$ to $20 \%$. In comparison, niphargids' activity ranged between $10 \%$ and peaks to even $50 \%$ [one individual], an activity never observed before.

\section{$500 \mu \mathrm{g} / \mathrm{L}$ copper pulse}

The second pulse experiment aimed to compare the reaction of G. fossarum and D. magna to a $500 \mu \mathrm{g} / \mathrm{l}$ copper pulse using the same biomonitoring technique [MFB] under same conditions of flow and temperature. Four individuals of each species were placed in the MFB test chambers and acclimatized for 2.5 hours in the raw intake water. Average activity of gammarids and daphnids were $39 \% \pm 3 \%$ and $40 \% \pm 3 \%$. The first reaction to the copper pulse of both implemented species were similar to gammarids' and niphargids' during the previous copper pulse although not as pronounced [Figure 9]. While both species maintained their average locomotive activity, variability over time decreased to $1 \%$ for gammarids and $2 \%$ for daphnids, i.e. stable high activity levels as indication of avoidance. Afterwards both species' activity decreased in a second phase. During this period, G. fossarum and D. magna reached the point of $<50 \%$ of their initial activity [ET50] after 8.7 and 6.6 hours. Strong difference in ET50 is mainly due to a strong drop in daphnid activity. 9.3 hours after start of exposure they reached a third phase in which average activity did not fall further but variability increased again. Activity of G. fossarum and D. magna were $13 \% \pm 5 \%$ SD and $10 \% \pm 5 \%$ SD, respectively. Furthermore, half an hour earlier and roughly after nine hours exposure, Gammaridae showed strong ventilation behaviour for two hours. In this experiment the BD reacted earlier although the BD TI showed elevated and fluctuating values already before the exposure. The BD TI rose 1.5 hours after exposure and stayed elevated for the rest of the provided data [14 hours].

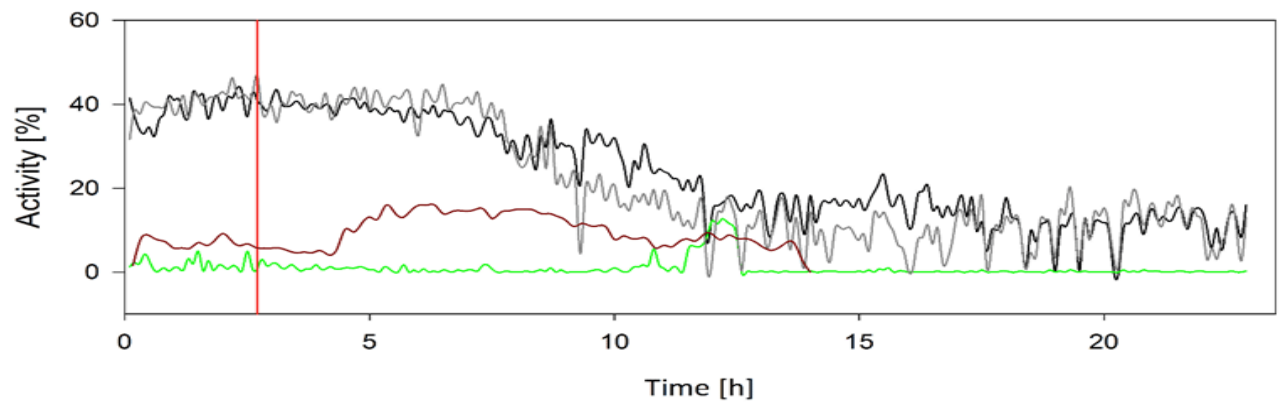

Figure 9: Result of the $500 \mu \mathrm{g} / \mathrm{l}$ copper pulse. The figure shows the average locomotion (black), ventilation (green) of $G$. fossarum and locomotion (grey) of D. magna. Furthermore, the Daphnia toxicity index (BD TI) is illustrated in dark red. Bright red vertical line mark the start of exposure to $500 \mu \mathrm{g} / \mathrm{l}$. 


\section{Discussion}

\section{Copper sensitivity}

\section{Acute}

Our determined 24-h LC50 of $610 \mu \mathrm{g} / \mathrm{l}$ for G.fossarum is high but in line with literature data that ranges for acute toxicity from $20 \mu \mathrm{g} / \mathrm{l}$ in soft water to $820 \mu \mathrm{g} / \mathrm{l}$ in saltwater [3,59]. Our laboratory experiments were performed at $10^{\circ} \mathrm{C}$, pH of 7.7 and moderate hardness. Low temperature and high $\mathrm{pH}$ decreases copper toxicity and thus leads to high LC50. Nevertheless, the increased mortality of the copper-exposed gammarids during the recovery period resulted in a strong decrease in LC50 [7-days] to $376 \mu \mathrm{g} / \mathrm{l}$ indicating long-lasting effects.

D. magna had lower LC50 values of $58 \mu \mathrm{g} / \mathrm{l}$ after exposure and $21 \mu \mathrm{g} / \mathrm{l}$ after seven days recovery. Unfortunately, mortality of the control group after recovery was $\sim 50 \%$, implying poor health of individuals or handling stress. Since both species' LC50 values in literature are strongly overlapping, a clear decision regarding their sensitivity cannot be drawn. A study trying to compare their sensitivity to a variety of substances came to the result of similar sensitivity $[4,44]$.

During the laboratory experiments the two tested stygal species appeared to be more tolerant to acute copper pulses, although long lasting exposure had strong effect on P. slavus. 24hour copper pulses showed no effect on either species' mortality. During the recovery period, there was likewise no change in survival rate. Their high tolerance may be due to their adaptation to groundwater conditions. In groundwater, the most limiting parameters appear to be food and oxygen supply [36]. Therefore, groundwater species possess a slower metabolism, lower basal activity and a longer life expectation compared to their relatives in surface waters. Slower metabolism and adaptation to low oxygen levels may be advantageous during copper exposure, since toxicokinetics act slower and gill impairment may not have as severe effects. Intriguingly regarding the behavioural responses, $N$. casparyi showed very similar behavioural changes to copper pollution as G. fossarum during the laboratory pulse experiments and the stepwise increasing copper pulse.

Besides the fixed endpoint evaluation using LC50, we also determined the time to reach 50\% effect [ET50]. Mean ET50 values towards $500 \mu \mathrm{g} / \mathrm{l}$ copper for G.fossarum, N.casparyi, and D.magna are $9.9 \mathrm{~h}, 6.5 \mathrm{~h}$, and 5.8 hours, respectively. The additional data for G. fossarum and D. magna match with the previously determined sensitivity using mortality as parameter. Daphnids' activity reduced by $50 \% 4.1$ hours earlier than gammarids did. In this regard, faster response argues for higher sensitivity of daphnids towards copper. Surprisingly, $N$. casparyi revealed strong behavioural changes. Reduction of locomotion by $50 \%$ indicates impact on the organisms. They reduced locomotion 0.7 hours later than daphnids, but 3.4 hours earlier than gammarids. Here $N$. casparyi appear to be likewise more sensitive than G. fossarum or alternatively respond more pronounced. Strong reduction in activity and short reaction time of N. casparyi indicate behavioural sensitivity, despite higher tolerance according to their higher survival rate. Using the ET50 approach we were able to assess and compare N. casparyis' sensitivity, although they did not show increased mortality after exposure. Thus, this approach not only gave us the opportunity to include $\mathrm{N}$. casparyi into the comparison, it furthermore provides higher resolution in cases of ties and thus may in future reduce the number of individuals needed to distinguish sensitivity. Unfortunately, in contrast to fixed endpoint evaluation [LC50], time-to-effect determination is only sparsely used to assess sensitivity towards pollutants, despite its advantages.

Eucyclops serrulatus, a test species of a so far unpublished study, appear to be the most sensitive species towards copper pollution in our acute toxicity tests. 24 -h LC50 was determined as being $25 \mu \mathrm{g} / \mathrm{l}$. LC50 further decreased with increasing exposure time for 48-h, 72-h, 96-h, and 7-d to $19 \mu \mathrm{g} / \mathrm{l}, 17 \mu \mathrm{g} / \mathrm{l}, 17 \mu \mathrm{g} / \mathrm{l}$, and $16 \mu \mathrm{g} / \mathrm{l}$, respectively [Gerhardt, in preparation]. Even low concentrations of $25 \mu \mathrm{g} / \mathrm{l}$ resulted in death of $50 \%$ of the individuals within 24 hours. Furthermore, in several laboratory copper pulse experiments using LimCo`s Microimpedance Sensor System [MSS] for small microscopic organisms, E. serrulatus showed promising, reproducible behavioural changes [Gerhardt, in preparation].

\section{Chronic}

Chronic exposure was not tested in D. magna. For N.casparyi there was no difference in survival rate between the control and any tested concentration. In contrast, G. fossarum and P.slavus showed a significant increase in mortality in the copper-exposed replicates. Here, rate of survival showed a strong dependence on concentration and duration of exposure. Both species showed a decrease of LC50 over time of exposure. LC50 of G. fossarum decreased from $268 \mu \mathrm{g} / \mathrm{l}[1 \mathrm{w}$ ] to $254 \mu \mathrm{g} / \mathrm{l}$ [2 w], $250 \mu \mathrm{g} / \mathrm{l}[3 \mathrm{w}]$ to $246 \mu \mathrm{g} / \mathrm{l}[4 \mathrm{w}$ ] during the exposure. Unfortunately, two control replicates showed surprisingly high mortality probably due to handling stress. Since high mortality in controls distorts toxicity, estimated LC50 is rather lower than the determined values. LC50 of P. slavus after four, five, and six weeks exposure were $217 \mu \mathrm{g} / \mathrm{l}$, $60 \mu \mathrm{g} / \mathrm{l}$, and $31 \mu \mathrm{g} / \mathrm{l}$, respectively. The strong decline in LC50 after 4 weeks indicates high impact on the organism.

The difference in acute and chronic toxicity may be due to dependence on species specific bioavailability, the rate of uptake, $\mathrm{Cu}$ homeostasis mechanisms, and furthermore depend on physicochemical conditions [10]. According to the congruent literature data copper toxicity increases with increasing temperature, decreasing DOC, $\mathrm{pH}$, major cations and hardness $[17,18,62]$. Furthermore, LC50 for all species decreases with exposure time.

\section{Ecological consequences}

The results of the present study are compared with literature values, and graphically presented in the species sensitivity 


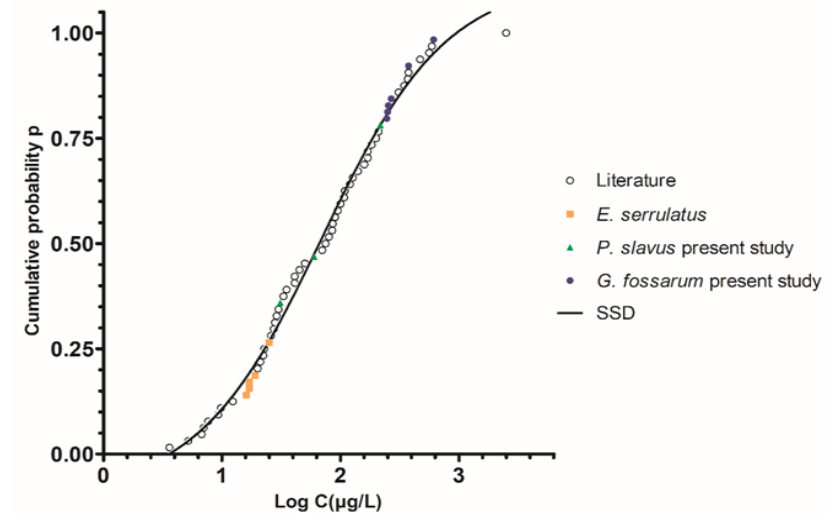

Figure 10: Species sensitivity distribution. SSD was compiled from literature data (hollow dots), data from the present study of E. serrulatus (orange squares), P. slavus (green triangles), and G. fossarum (purple dots).

distribution in Figure 10. Across literature there are strong discrepancies regarding species specific sensitivity towards copper. For example, experiments with Daphnia magna claim 48-h EC50 of 7.7-430 $\mu \mathrm{g} \mathrm{Cu} / \mathrm{l}$ and 48-h LC50 of 5-86 $\mu \mathrm{g} \mathrm{Cu} / \mathrm{l}$ $[38,43]$. For Gammarus pulex, 24-h LC50 of 86-375 $\mu \mathrm{g} / \mathrm{l}$ and 96-h LC50 of $21 \mu \mathrm{g}-370 \mathrm{Cu} / \mathrm{l}[69,73]$ were reported, making comparisons difficult. The figure shows that E.serrulatus is one of the earliest affected species. Prolonged exposure to low to moderate concentrations of copper showed strong impact on P. slavus. Comparison of our experimental results of G. fossarum to literature indicate late impact relative to the other species. Using the SSD we defined the HC5 and the PAF as being $7 \mu \mathrm{g} / \mathrm{l}$ and $10.7 \%$, respectively.

Beyond the implication for the directly affected organisms through acute or chronic exposure, this has also consequences for other members of the community and thus the whole ecosystem, since the presented species represent important species of the lower trophic levels report about the top-down control of D. magna over algal blooms $[15,16,65]$. Furthermore, diminishing low trophic levels also leads to strong bottom-up effects $[22,77]$ decreasing predator abundance i.e. fishes and therefore affecting fisheries [12]. Beside these more prominent effects of surface water bodies, disturbances of water communities have huge impact on water body services. For groundwater these were reviewed by Griebler [35]. but because there is high interaction between surface and groundwater, they strongly depend on each other [78]. Groundwater ecosystem services include

" 1 purification of water and its storage in good quality for decades and centuries.

2 active biodegradation of anthropogenic contaminants and inactivation and elimination of pathogens.

3 nutrient recycling, and

4 mitigation of floods and droughts."
Accordingly, species richness, abundance and activity are crucial for maintaining these services.

\section{Field experiment}

During the field experiments G. fossarum and N. casparyi approved their sensitivity to sub-lethal concentration of 100 $\mu \mathrm{g} / \mathrm{l}$. They reacted with consistent and reproducible behavioural changes in the MFB. The immediate avoidance response of G.fossarum is sufficient to elucidate an alarm and the subsequent decline in locomotion of the two species represent a second, more severe alarm for pollutant detection. The pattern of initial escape/avoidance response followed by subsequent decreased locomotion was already described before [27, 29, 31]. In earlier field experiments in a copper-polluted stream, G.pulex reacted with increased locomotion to an employed copper pulse of about $63 \mu \mathrm{g} / \mathrm{l}[30]$.

During our second copper pulse experiment using G. fossarum and D. magna, a similar reaction could be observed, although the reaction was not as pronounced in neither of the employed species. The reduction in variability combined with constant high activity was a first and almost immediate alarm sign. This early response was followed by a delayed and strong reduction in activity of G. fossarum and D. magna in the MFB. They reduced their activity by $>50 \%$ after 8.7 and 6.6 hours, respectively, representing their ET50. The time to effect determination allows for another adjustable parameter for monitoring. The two species in the MFB reduced their activity almost alike. Differences in ET50 are mainly due to a single drop in activity that crossed EC50 of D. magna but closely missed EC50 of G. fossarum. As a last irreversible effect, one or multiple animals showing no activity can be determined as immobile/dead.

During the stepwise increasing copper pulse, the BD TI only started to increase upon $500 \mu \mathrm{g} / \mathrm{l}$ copper. This was 4.5 hours later than G.fossarum and N. casparyi. During the second pulse experiment, BD TI rose 1.5 hours after exposure. Compared to the initial response of the MFB species, response is late but still earlier than the subsequent severe decrease in activity. The BD TI is an integration of multiple behavioural parameters like average speed, swimming height, distance, and others. Based on these factors anomalies lead to elevation of the BD TI. Heightened BD TI values before start of the $500 \mu \mathrm{g} / \mathrm{l}$ pulse may have already previously generated an alarm signal and indicate problematic preconditions like wrong number of daphnids, poor health, stress or dead daphnids. In contrast to the MFB, the BD heats the incoming water to $20^{\circ} \mathrm{C}$, artificially illuminate the test chamber and contain algae as food source. Heating and filtering the water, both additional efforts, portray "interference" in the natural conditions. Higher water temperature increases metabolism and might cause a rise in "sensitivity due to higher metabolism". This effect may not reflect natural conditions, therefore seem unsuitable for field experiments and furthermore hampers extrapolation of laboratory experimental results into implication on ecosystems [37]. The same is true for artificial light. Although 
the light source probably does not produce UV light, light may result in a positive or negative compound toxicity [41]. Furthermore pollutants were shown to alter circadian rhythms in the field, implications that would be hidden if artificial light was implemented permanently [31]. During the field experiment, in each period, the BD was maintained several times and daphnids were exchanged at least twice. Together with the two cultivations [algae and daphnids], this highlight higher maintenance efforts compared to the MFB.

\section{Biomonitoring}

Storey [71] and Bae [5] reviewed technologies to monitor drinking water quality. The advantage of using whole organism is here the integration of numerous toxins including additive or synergistic effects that are often disregarded in toxicity experiments but may play a big role in water quality. There are solid instruments for $\mathrm{pH}$, chlorine, total organic carbon [TOC], conductivity, temperature, and more advanced laser-based technologies, which are designed for the continuous online measurement of particles in water. "Furthermore, instrumentation including gas chromatographyemass spectrometry [GCeMS], an automated system that can be used to detect volatile trace organic micropollutants, liquid chromatographyeMS [LCeMS] and high-performance liquid chromatography [HPLC]", both very expensive techniques are in use [71].

Further online biomonitors base on luminescence of bacteria, growth or photosynthesis of algae or behavioural changes of multicellular species like crustacean or fish $[5,19,71]$. Biological early warning systems [BEWS] have to fulfil several properties: The system must be affordable in acquisition and maintenance, it must respond fast with high accuracy, it should have a broad applicability, and the selected test organism must be sensitive and appropriate for the demands of application and the prevalent conditions. Despite the substantial progress made in recent years, the authors highlight the lack of a device comprising all desired characteristics. Microsensor and nanotechnology based systems appear too expensive and often not reliable. Devices based on algae or other species' growth show an unfavourable lag time in response [71]. Systems using aquatic animals are usually restricted in the deployment of a particular species which confines the application field due to their sensitivity. Furthermore, depending on the species, a second culture [algae] may be needed as food for daphnids, which in turn increases maintenance efforts.

During the present study the MFB proved to be affordable in acquisition and low in maintenance efforts due to its simple and robust technology, setup and handling. Second, since the MFB is not restricted to a particular species, we successfully used both surface and groundwater crustaceans as well as microscopic species such as D. magna and E. serrulatus. Because the MFB is not based on optical measurements, a variety of different species and media [unfiltered water, sediment] can be applied, which enable the application to a wide range of areas $[32,33$,
39, 42, 70]. The MFB can operate with untreated raw water [no filtration, no heating needed] in the waterworks, hence reduces the maintenance efforts and recording of artefacts, and increases the ecological relevance of monitoring data. Because of this, the realistic in situ availability and abiotic conditions of the chemicals are not changed and locally resident species can be used as bioindicator species in the biomonitor. Tests using G. fossarum or N. casparyi showed that maintenance intervals of $>14$ days in the MFB are conceivable. These are larger than the usual stand-alone time for biomonitors using daphnids, which is on week.

Experiments using copper as toxicant showed toxic effect of chronic exposure on P. slavus, but not in acute pulses, excluding it from monitoring usage. Our study revealed fast, sensitive responses in N. casparyi similar to G. fossarum. However, difficult capture and yet unknown breeding conditions represent high hurdles to use these groundwater species in continuous biomonitoring of groundwater and drinking water. Furthermore, the lack of toxicity data for stygal species display a problem regarding the determination of applicability.

D. magna proved its applicability as biomonitoring species in several studies. Nevertheless, providing a piece of an alder leave as food source for G. fossarum is feasible and very low in effort. Thus, maintenance cost and time is low. High abundance and broad distribution in water bodies qualify G. fossarum as a common indicator for pollution. The large availability of toxicity data towards numerous natural or anthropogenic compounds enable the use of G. fossarum in a broad range of applications. Furthermore, it represents a robust, but still sensitive and fast reacting species. Therefore, we recommend G. fossarum as a suitable species for biomonitoring in a wide range of fields.

\section{Conclusion}

From the results of this study the following conclusions can be drawn: Regarding mortality in acute copper pulses, D. magna is the most sensitive species, followed by G. fossarum. Here the two stygal species appear to be fairly tolerant. However, time-toeffect evaluation of laboratory experiments prove the sensitivity of N. casparyi in defiance of the lack of increased mortality/ immobility after exposure. Nevertheless, difficult breeding or capture conditions might still exclude N. casparyi from application in online biomonitoring systems despite very low maintenance cost and effort. Therefore, our findings support G. fossarum as the species of choice for monitoring both, surface and groundwater quality. High sensitivity, fast response to several toxicants, the applicability to a variety of conditions and low maintenance requirements highlight $\mathrm{G}$. fossarum as the most promising test organism for online biomonitoring.

Furthermore, field experiments showed escape responses of G. fossarum and N. casparyi, that are faster than the established biomonitor using daphnids. Throughout the time in the waterworks, the MFB represented a valuable tool for drinking water intake surveillance. Through its high flexibility, the MFB portrays a useful device for future water quality control in a wide range of fields. 


\section{Acknowledgements}

We thank Nadine Leubner and Anna Petri for collecting acute toxicity data of G. fossarum, N. casparyi, and P. slavus and Emerik Leaković for acquiring chronic toxicity data, of G. fossarum. Many thanks to the local waterworks for providing the possibility to conduct our field experiments, the physicochemical data and the BD TI values for comparison of the monitoring systems. We are thankful for the chemical analytics by Technologiezentrum Wasser [TZW] in Karlsruhe and Shaw Civitarese for his linguistic support.

This project is supported by the German Federal Ministry of Education and Research [BMBF] as part of the funding measure "Regional Water Resources Management for Sustainable Protection of Waters in Germany" - ReWaM [GroundCare: funding code 033W037H]

\section{Declaration of interest}

\section{Conflicts of interest: none}

\section{References}

1. Arias-Estévez M, López-Periago E, Martínez-Carballo E, SimalGándara J, Mejuto J-C, and García-Río L. The mobility and degradation of pesticides in soils and the pollution of groundwater resources. Agriculture, Ecosystems \& Environment. 2008;123(4):247-260.

2. Arnold, DE. INGESTION, ASSIMILATION, SURVIVAL, AND REPRODUCTION BY DAPHNIA PULEX FED SEVEN SPECIES OF BLUEGREEN ALGAE1,2. Limnology and Oceanography. 1971;16(6):906920.

3. Arthur JW. and Leonard EN. Effects of copper on Gammarus pseudolimnaeus, Physa integra, and Campeloma decisum in soft water. Journal of the Fisheries Board of Canada. 1970;27(7):1277-1283.

4. Ashauer R, Hintermeister A, Potthoff E, and Escher, BI. Acute toxicity of organic chemicals to Gammarus pulex correlates with sensitivity of Daphnia magna across most modes of action. Aquatic Toxicology. 2011;103(1):38-45.

5. Bae MJ. and Park YS. Biological early warning system based on the responses of aquatic organisms to disturbances: a review. Science of The Total Environment. 2014;466:635-649.

6. Baird DJ and Barata C. Variability in the response of Daphnia clones to toxic substances: are safety margins being compromised?. Springer Science \& Business Media.1999;20:399-406.

7. Barrell R. and Rowland M. The relationship between rainfall and well water pollution in a West African (Gambian) villaǵe. Epidemiology \& Infection. 1979;83(1):143-150.

8. Bork J. and Hahn HJ. Groundwater and Biodiversity. Published by: Federal Ministry for the Environment, Nature Conservation and Nuclear Safety (BMU). Germany; Public Relations Division: 2008.

9. Brooks SJ. and Mills CL. The effect of copper on osmoregulation in the freshwater amphipod Gammarus pulex. Comp Biochem Physiol A Mol Integr Physiol. 2003;135(4):527-537.

10. Camakaris J, Voskoboinik I. and Mercer J. Molecular mechanisms of copper homeostasis. Biochem Biophys Res Commun. 1999;261(2):225-232.
11. Cao $\mathrm{Z}$ and Hu Z. Copper contamination in paddy soils irrigated with wastewater. Chemosphere. 2000;41(1):3-6.

12. Carpenter SR, Kitchell JF, Hodgson JR. Cascading trophic interactions and lake productivity. BioScience. 1985;35(10): 634-639.

13. Chevalier J, Harscoët E, Keller M, Pandard P, Cachot J, Grote M. Exploration of Daphnia behavioral effect profiles induced by a broad range of toxicants with different modes of action. Environ Toxicol Chem. 2015;34(8):1760-1769.

14. D'souza S. Microbial biosensors. Biosensors and Bioelectronics. 2001;16(6):337-353.

15. Dahl J. Effects of a benthivorous and a drift-feeding fish on a benthic stream assemblage. Oecologia. 1998;116(3): 426-432.

16. Dangles O, Gessner MO, Guerold F, Chauvet E. Impacts of stream acidification on litter breakdown: implications for assessing ecosystem functioning. Journal of Applied Ecology. 2004;41(2):365-378.

17. De Schamphelaere KA, Heijerick DG, Janssen CR. Refinement and field validation of a biotic ligand model predicting acute copper toxicity to Daphnia magna. Comp Biochem Physiol C Toxicol Pharmacol. 2002;133(1-2):243-258.

18. De Schamphelaere KA, Vasconcelos FM, Tack FM, Allen HE, Janssen CR. Effect of dissolved organic matter source on acute copper toxicity to Daphnia magna. Environ Toxicol Chem. 2004;23(5):1248-1255.

19. Elad T and Belkin S. Whole-cell biochips for online water monitoring. Bioengineered. 2012;3(2):124-128.

20. Ferrari DC and Hebert PD. The induction of sexual reproduction in Daphnia magna: genetic differences between arctic and temperate populations. Canadian Journal of Zoology. 1982;60(9):2143-2148.

21. Flemming CA and Trevors JT. Copper Toxicity and Chemistry in the Environment - a Review. Water Air and Soil Pollution. 1989;44(12):143-158.

22. Frederiksen M, Edwards M, Richardson AJ, Nicholas $\mathrm{CH}$, Wanless S. From Plankton to Top Predators: Bottom-up Control of a Marine Food Web across Four Trophic Levels. Journal of Animal Ecology. 2006;75(6):1259-1268.

23. Friberg N, Bonada N, Bradley DC, Dunbar MJ, Edwards FK, Grey J, et al. Biomonitoring of human impacts in freshwater ecosystems: the good, the bad and the ugly. Advances in Ecological Research. 2011;44:1-68.

24. Gadgil A. DRINKING WATER IN DEVELOPING COUNTRIES. Annual Review of Energy and the Environment. 1998;23(1):253-286.

25. Gerhardt A. Monitoring behavioural responses to metals inGammarus pulex (L.)(Crustacea) with impedance conversion. Environmental Science and Pollution Research. 1995;2(1):15-23.

26. Gerhardt A. Behavioural early warning responses to polluted water. Environmental Science and Pollution Research. 1996;3(2):63-70.

27. Gerhardt A. Biomonitoring of polluted water. Trans Tech Publications Ltd. 2000;

28. Gerhardt A. Aquatic behavioral ecotoxicology-prospects and limitations. Human and Ecological Risk Assessment. 2007;13(3):481491.

29. Gerhardt A, Bisthoven L, Penders E. Quality Control of Drinking Water from the River Rhine with the Multispecies Freshwater Biomonitor. Aquatic Ecosystem Health and Management. 2003;6(2):159-166.

30.Gerhardt A, Carlsson A, Ressemann C, Stich KP. New online biomonitoring system for Gammarus pulex (L.)(Crustacea): in situ 
test below a copper effluent in south Sweden. Environmental Science \& Technology. 1998;32(1):150-156.

31. Gerhardt A, Janssens de Bisthoven L, Soares AM. Evidence for the stepwise stress model: Gambusia holbrooki and Daphnia magna under acid mine drainage and acidified reference water stress. Environmental Science \& Technology, 2005;39(11):4150-4158.

32. Gerhardt A, Schmidt S, Hoss S. Measurement of movement patterns of Caenorhabditis elegans (Nematoda) with the Multispecies Freshwater Biomonitor (MFB)--a potential new method to study a behavioral toxicity parameter of nematodes in sediments. Environ Pollut. 2002;120(3):513-516.

33. Gerhardt A, Svensson E, Clostermann M, Fridlund B. Monitoring of behavioral patterns of aquatic organisms with an impedance conversion technique. Environment International. 1994;20(2):209219.

34. Gleick PH. Water and terrorism. Water Policy. 2006;8(6):481-503.

35. Griebler C, Avramov M. Groundwater ecosystem services: a review. Freshwater Science. 2014;34(1):355-367.

36. Hahn HJ. The GW-Fauna-Index: A first approach to a quantitative ecological assessment of groundwater habitats. Limnologica - Ecology and Management of Inland Waters. 2006;36(2):119-137.

37. Heugens EH, Jager T, Creyghton R, Kraak MH, Hendriks AJ, Van Straalen NM, et al. Temperature-dependent effects of cadmium on Daphnia magna: accumulation versus sensitivity. Environmental Science \& Technology. 2003;37(10):2145-2151.

38. Hodson P, Borgmann U, Shear H. Nriagu IO.(Ed). Copper in the environment. Part 2: Health effects, John Wiley, New York. 1979;

39. Janssens de Bisthoven L, Gerhardt A, Soares AM. Effects of acid mine drainage on larval Chironomus (Diptera, Chironomidae) measured with the Multispecies Freshwater Biomonitor. Environ Toxicol Chem. 2004;23(5):1123-1128.

40. Jeon J, Kim JH, Lee BC, Kim SD. Development of a new biomonitoring method to detect the abnormal activity of Daphnia magna using automated Grid Counter device. Science of The Total Environment. 2008;389(2-3);545-556.

41. Kim J, Park J, Kim P G, Lee C, Choi K, Choi K. Implication of global environmental changes on chemical toxicity-effect of water temperature, $\mathrm{pH}$, and ultraviolet $\mathrm{B}$ irradiation on acute toxicity of several pharmaceuticals in Daphnia magna. Ecotoxicology. 2010;19(4):662-669. Doi: 10.1007/s10646-009-0440-0

42. Kirkpatrick AJ, Gerhardt A, Dick JT, Laming P, Berges JA. Suitability of Crangonyx pseudogracilis (Crustacea: Amphipoda) as an early warning indicator in the multispecies freshwater biomonitor. Environ Sci Pollut Res Int. 2006;13(4):242-250.

43. Kramer KJ, Jak RG, van Hattum B, Hooftman RN, Zwolsman JJ. Copper toxicity in relation to surface water-dissolved organic matter: biological effects to Daphnia magna. Environ Toxicol Chem. 2004;23(12):2971-2980.

44. Kunz PY, Kienle C, Gerhardt A. Gammarus spp. in aquatic ecotoxicology and water quality assessment: toward integrated multilevel tests. Rev Environ Contam Toxicol. 2010;205:1-76.

45. Lagarde $\mathrm{F}$ and Jaffrezic-Renault N. Cell-based electrochemical biosensors for water quality assessment. Analytical and bioanalytical chemistry. 2011;400(4):947.
46. Larson SJ, Capel PD, Majewski M. Pesticides in surface waters: Distribution, trends, and governing factors. CRC Press. 1997;

47. Lazarova V, Levine B, Sack J, Cirelli G, Jeffrey P, Muntau H, et al. Role of water reuse for enhancing integrated water management in Europe and Mediterranean countries. Water Science and Technology. 2001;43(10):25-33.

48. Lee EJ and Schwab KJ. Deficiencies in drinking water distribution systems in developing countries. J Water Health. 2005;3(2):109-127.

49. Lei Y, Chen W, Mulchandani A. Microbial biosensors. Analytica chimica acta. 2006;568(1):200-210.

50. Maltby L. Sensitivity of the crustaceans Gammarus pulex (L.) and Asellus aquaticus (L.) to short-term exposure to hypoxia and unionized ammonia: observations and possible mechanisms. Water Res. 1995;29(3):781-787.

51. McDonald RI, Green P, Balk D, Fekete BM, Revenga C, Todd M, et al. Urban growth, climate change, and freshwater availability. Proceedings of the National Academy of Sciences. 2011;108(15):6312-6317.

52. Meulenberg EP, Stoks PG. Water quality control in the production of drinking water from river water. The application of immunological techniques for the detection of chlorophenoxy acid herbicides (2, 4-D). Analytica chimica acta. 1995;311(3):407-413.

53. Nations U. World Urbanization Prospects: The 2014 Revision, Highlights. Department of Economic and Social Affairs. Population Division, United Nations.

54. Niemczynowicz J. Urban hydrology and water management - present and future challenges. Urban Water. 1999;1(1):1-14.

55. OECD . Test No. 202: Daphnia sp. Acute Immobilisation Test. OECD Publishing. 2004;

56. Okun D. Water reuse introduces the need to integrate both water supply and wastewater management at local and regulatory levels. Water Sci Technol. 2002;46(6-7):273-280.

57. Polunin NVC. Biological Indicators of Freshwater Pollution and Environmental Management, by HellawellJ.M.. Elsevier Applied Science Publishers, London \&amp; New York: xiii +518 pp., 89 illustrations, $23 \times 15 \times 4 \mathrm{~cm}$, $€ 65$ hard cover, 1986. Environmental Conservation. 1987;14(2):188.

58. Posthuma L, Suter II GW, Traas TP. Species sensitivity distributions in ecotoxicology. 2001;CRC press.

59. Prato E, Biandolino F, Scardicchio C. Test for acute toxicity of copper, cadmium, and mercury in five marine species. Turkish Journal of Zoology. 2006;30(3):285-290.

60. Rétaux S, Casane D. Evolution of eye development in the darkness of caves: adaptation, drift, or both? Evodevo. 2013;4:26.

61. Rozemeijer J, Van der Velde Y, Van Geer F, Bierkens M, Broers H. Direct measurements of the tile drain and groundwater flow route contributions to surface water contamination: From field-scale concentration patterns in groundwater to catchment-scale surface water quality. Environ Pollut. 2010;158(12):3571-3579.

62. Santore RC, Di Toro DM, Paquin PR, Allen HE, Meyer JS. Biotic ligand model of the acute toxicity of metals. 2. Application to acute copper toxicity in freshwater fish and Daphnia. Environ Toxicol Chem. 2001;20(10):2397-2402.

63. Schiff K, Brown J, Diehl D, Greenstein D. Extent and magnitude of copper contamination in marinas of the San Diego region, California, 
USA. Marine Pollution Bulletin. 2007;54(3):322-328.

64. Schmoll O, Howard G, Chilton G, Chorus I. Protecting groundwater for health: managing the quality of drinking-water sources. World Health Organization. 2006;

65. Shapiro J. Hypertrophic ecosystems. Springer. 1980; 105-116.

66. Simonovic SP. World water dynamics: global modeling of water resources. J Environ Manage. 2002;66(3):249-267.

67. Soares AM, Baird DJ, Calow P. Interclonal variation in the performance of Daphnia magna Straus in chronic bioassays. Environ Toxicol Chem. 1992;11(10):1477-1483.

68. Sophocleous M. Interactions between groundwater and surface water: the state of the science. Hydrogeology journal. 2002;10(1):52-67.

69. Stephenson RR. Effects of water hardness, water temperature, and size of the test organism on the susceptibility of the freshwater shrimp, Gammarus pulex (L.), to toxicants. Bull Environ Contam Toxicol. 1983;31(4):459-466.

70. Stewart SC, Dick JTA, Laming PR, Gerhardt A. Assessment of the Multispecies Freshwater Biomonitor (MFB) in a marine context: the Green crab (Carcinus maenas) as an early warning indicator. J Environ Monit. 2016;12(8):1566-1574.

71.Storey MV, Van der Gaag B, Burns BP. Advances in on-line drinking water quality monitoring and early warning systems. Water Res. 2011;45(2):741-747.
72. Syracuse Research Corporation., United States. Department of Health and Human Services., United States. Agency for Toxic Substances and Disease Registry. and United States. Public Health Service. (2004) Toxicological profile for copper, p. volumes, Agency for Toxic Substances and Disease Registry, Atlanta, GA.

73. Taylor EJ, Maund SJ, Pascoe D. Toxicity of four common pollutants to the freshwater macroinvertebrates Chironomus riparius Meigen (Insecta: Diptera) andGammarus pulex (L.)(Crustacea: Amphipoda). Arch Environ Contam Toxicol. 1991;21(3):371-376.

74. Tomasiks P, Warren DM. The use of Daphnia in studies of metal pollution of aquatic systems. Environmental Reviews. 1996;4(1):2564.

75. United States. Environmental Protection Agency. Prevention, P. and Substances, T. Ecological Effects Test Guidelines: OPPTS 850.1020 : Gammarid Acute Toxicity Test, U.S. Environmental Protection Agency, Prevention, Pesticides and Toxic Substances. 1996;

76. Van der Schalie WH, Shedd TR, Knechtges PL, Widder MW. Using higher organisms in biological early warning systems for real-time toxicity detection. Biosens Bioelectron. 2001;16(7-8):457-465.

77. Wallace JB, Eggert SL, Meyer JL, Webster JR. Multiple trophic levels of a forest stream linked to terrestrial litter inputs. Science. 1997;277(5322):102-104.

78. Winter TC. Ground water and surface water: a single resource, DIANE Publishing Inc. 1998; 